\title{
DI DIESEL ENGINE COMBUSTION VISUALIZED BY COMBINED LASER TECHNIQUES
}

\author{
A. ARNOLD, F. DINKELACKER, T. HEITZMANN, P. MONKHOUSE, M. SCHÄFER, \\ V. SICK AND J. WOLFRUM \\ Physikalisch-Chemisches Institut der Universität Heidelberg, \\ Im Neuenheimer Feld 253, W-6900 Heidelberg, Germany
}

AND

W. HENTSCHEL AND K.-P. SCHINDLER

Research Division, Volkswagen AG, W-3180 Wolfsburg, Germany

\begin{abstract}
In this work we demonstrate that the progress of the combustion cycle in a four-cylinder (in-line) $1.9 \mathrm{I}$ direct injection Diesel engine can be studied effectively using different laser visualization techniques. Direct optical access to the piston bowl was facilitated by inserting quartz windows in one of the pistons. The flow field at the time of injection was characterized by seeding the flow and illuminating the piston bowl with a laser light sheet. Fuel spray development, auto-ignition and flame propagation in a Diesel cycle were followed by laser shadowgraphy and high speed cinematography while simultaneous laser induced fluorescence (LIF) and Mie scattering images were taken to distinguish the fuel distribution in the liquid and vapor phase. In addition, two dimensional distributions of $\mathrm{OH}$ and NO, formed during $n$-heptane/air combustion in the same engine, were recorded in the pressure range 5 to 50 bar by LIF following narrowband excitation using tunable excimer lasers. Finally, further work, designed to obtain quantitative images and hence data for comparison with model calculations, is outlined.
\end{abstract}

\section{Introduction}

In spite of the high efficiency already achieved by Diesel engine technology, there is still potential to reduce emissions of soot, $\mathrm{NO}_{x}$ and $\mathrm{CO}_{2}$ by improving fuel consumption even further, in order to meet increasingly stringent requirements for future ultra-low emission vehicles (ULEV). To do this, it is essential to improve our detailed understanding of the processes occurring during Diesel combustion, by both experimental determination of key parameters and comparison with model calculations. ${ }^{1}$ For instance, knowledge of the flow field (in particular during injection) in the combustion chamber is critical for mixture formation in the engine. Measurements of the fuel distribution in both liquid and gas phases at various stages of the engine cycle must be carried out in order to understand spray behavior, mixture formation, self-ignition and flame propagation. The distribution of key transient species such as the $\mathrm{OH}$ radical, which can serve to monitor the progress of combustion, and pollutants such as $\mathrm{NO}$ should also be determined. Finally, it is essential to obtain temperature fields and correlate these with species distributions.

Diesel combustion is a turbulent, two-phase, dif- fusion-controlled process which can be investigated most effectively by recording the instantaneous structure of flow field parameters using multidimensional visualization methods with high temporal and spatial resolution. Recent publications have described applications of nonintrusive techniques such as laser schlieren, ${ }^{2,3}$ laser shadowgraphy, ${ }^{2,4-6}$ particle image (or tracking) velocimetry, 7,8 2D-LIF (laser induced fluorescence, ${ }^{9-15}$ and Mie scattering $3,9,10,15,16$ in engine combustion, using laser light for illumination or excitation of species of interest. For the 2D-LIF detection of $\mathrm{OH}, 9,10,12,14$ $\mathrm{O}_{2},{ }^{14} \mathrm{NO}^{14}$ and other molecules, tunable, high power UV-excimer lasers are available which allow specific excitation and single-shot imaging of these key species.

In this work we have followed the progress of fuel injection, vaporization, autoignition and combustion in a transparent DI Diesel engine by direct visualization. Flow fields were obtained from laser light sheet experiments. Using Diesel as fuel, spray propagation, autoignition and combustion were visualized with high temporal resolution using laser shadowgraphy in conjunction with high speed cinematography. However, the shadowgraphy technique only provides limited information on the in- 
homogeneous mixture field. Because Diesel fuel already contains fluorescing components, LIF in the UV can be used to monitor the fuel distribution in the liquid and vapor phase. By detecting fluorescence and (Mie) scattered light separately, liquid droplets can be distinguished from the vapor fuel. In the second part of this study, OH and NO, formed during combustion of $n$-heptane/air mixtures were detected by 2D-LIF. In this case, nheptane was chosen as fuel since it is frequently used for modelling purposes and because it is wellcharacterized (e.g. with respect to spray behavior, ignition mechanism).

Thus by combining a variety of laser visualization techniques one can expect to obtain complementary information on different aspects of Diesel combustion and ultimately, to build up a data basis for development and verification of combustion models for Diesel engines.

\section{Experimental}

Measurements were performed on a four-cylinder (in-line), 1.9 l direct injection Diesel engine (Fig. 1), modified to allow direct optical access of a laser light sheet to the piston bowl. For access of the laser light sheet, quartz plates were inserted into the top of one of the four pistons (Fig. 2). The combustion system is characterized by a swirl inlet port and a centrally located, five-hole injection nozzle. Measurements on Diesel combustion were performed at an engine speed at $2000 \mathrm{rpm}$, whereas those using $n$-heptane as fuel were done at 1000 rpm.

Using $n$-heptane as fuel, the engine could be operated for many minutes before the windows became obscured with soot. Thus the detection system could be adjusted during operation. On the other hand, with Diesel as fuel, all windows were covered with soot within a few seconds.

\section{Flow Field Visualization:}

To observe the temporal development of the flow field, the air flow was seeded with lycopodium spores (mean diameter ca. $36 \mu \mathrm{m}$ ) in the intake manifold and the area of the combustion bowl illuminated through quartz glass windows in the cylinder wall and the piston crown. For this purpose, light from a $20 \mathrm{~W} \mathrm{cw-argon} \mathrm{ion} \mathrm{laser} \mathrm{was} \mathrm{formed} \mathrm{into} \mathrm{a} \mathrm{light}$ sheet using a cylindrical lens. The movement (path lines) of the spores was filmed with a high speed camera $(\sim 4000$ frames/sec) through the window in the piston bowl bottom and a fixed $45^{\circ}$ mirror inserted from the side.

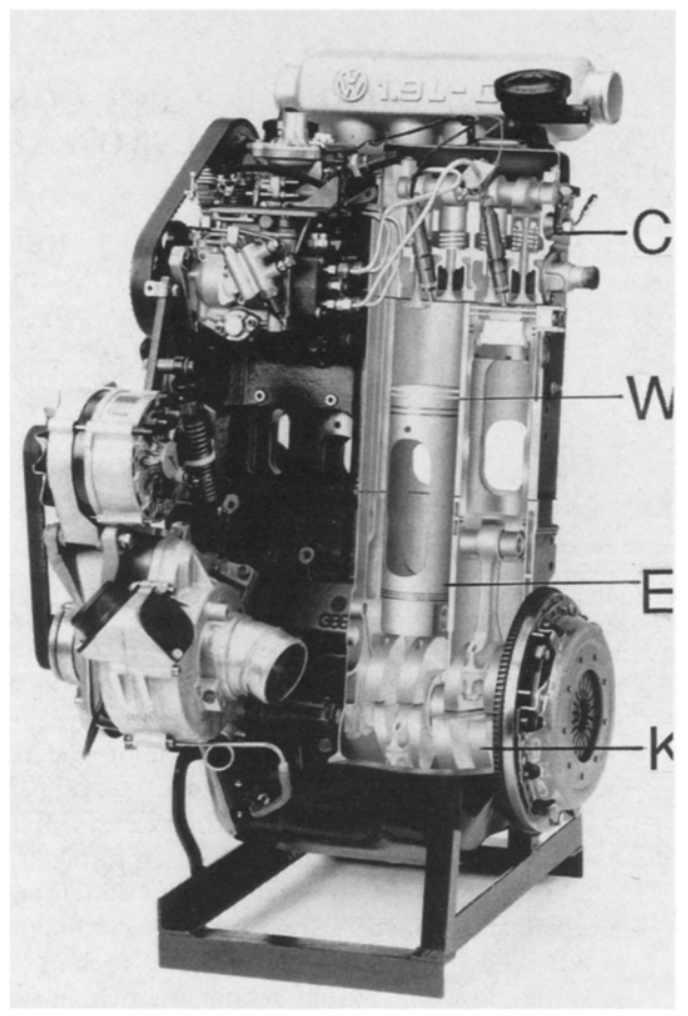

Fic. 1. 1.91 direct injection Diesel engine: $C=$ cylinder head; $W=$ quartz windows for optical access; $E=$ elongated piston; $K=$ crank case.

\section{Laser Shadowgraphy:}

For these experiments, the combustion chamber was illuminated from below with a diffuse, pulsed $(\sim \mu s)$ laser beam via the piston crown and the plane reflecting surfaces at the cylinder head (Fig. 3). The camera was operated at 8000 frames/sec, giving a temporal resolution of $125 \mu \mathrm{s}$ from frame to frame, corresponding to $1.5^{\circ}$ crank angle at $2000 \mathrm{rpm}$ en-

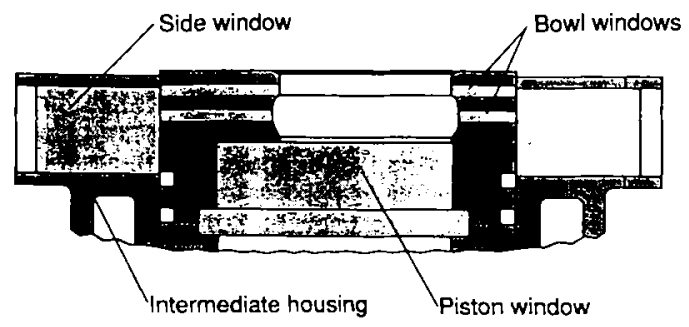

FIG. 2. Arrangement for optical access to the combustion chamber. 


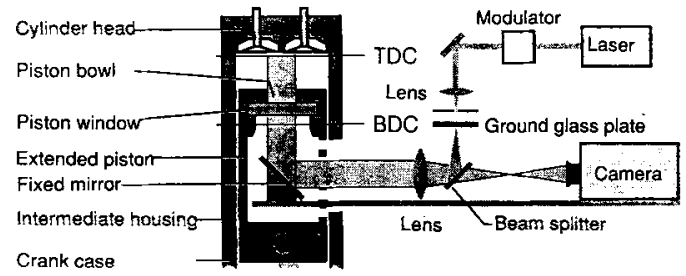

FIG. 3. Set-up for shadowgraphy experiments.

gine speed. The fuel sprays were observed as dark clouds on a bright background and following ignition, flame luminescence during combustion was also recorded.

\section{D-LIF and Mie Scattering:}

$\mathrm{XeCl}$-excimer laser light at $308 \mathrm{~nm}(20 \mathrm{~mJ})$ was used to excite broadband fluorescence in the fuels. For excitation of $\mathrm{OH}$ and NO produced in $n$-heptane/air combustion, excimer lasers at $248 \mathrm{~nm}$ (10 $\mathrm{mJ})$ and $193 \mathrm{~nm}(6 \mathrm{~mJ})$ respectively were employed in the tunable mode. The rectangular laser beam was shaped into a light sheet, $1 \mathrm{~mm}$ thick $(0.5 \mathrm{~mm}$ for $\mathrm{OH}$ measurements), $10 \mathrm{~mm}$ wide.

The set up for 2D-imaging is shown in Fig. 4 . LIF and Mie scattering images were recorded simultaneously using beam splitters to direct the light to two separate CCD cameras. The image intensifiers of the cameras could be gated by a trigger circuit. It was verified that by using gate times of 50 $\mathrm{ns}$, flame emission could be completely suppressed.

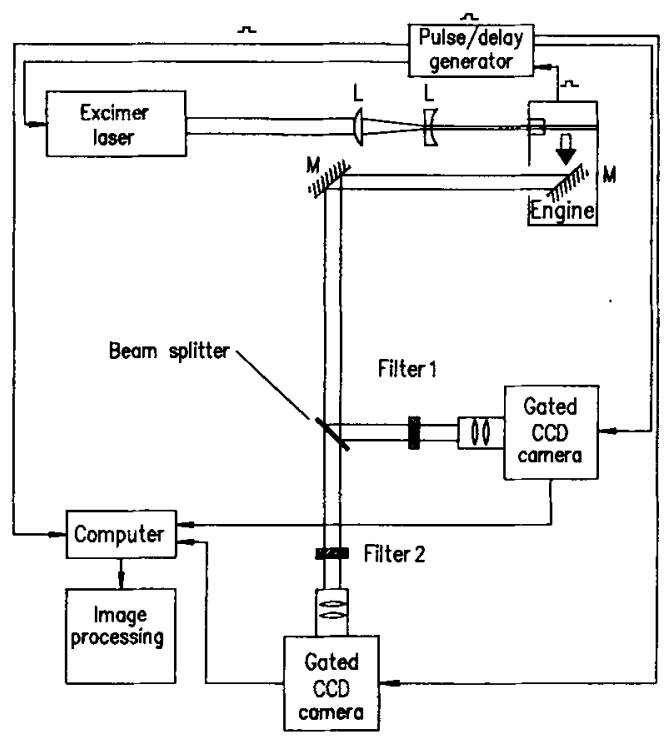

FIG. 4. Set-up for LIF/Mie imaging.

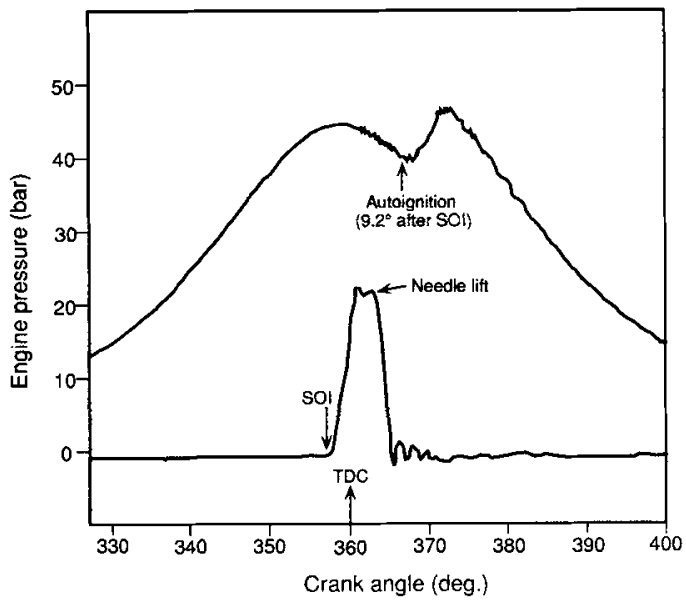

Fig. 5. Pressure history for a typical Diesel cycle (engine speed $2000 \mathrm{rpm}$, fuel mass $8 \mathrm{mg}$ injected per cycle. $T D C=$ top dead center; $S O I=$ start of injection; max. engine pressure 46.7 bar; max. pipe pressure 250 bar.

Images could be recorded at the operating speed of the engine using video recorders, so that essentially for every cycle one pair of pictures could be recorded.

For fluorescence imaging of NO, the $D^{2} \Sigma-X^{2} \Pi$ transition, (0, 1)-band near $193 \mathrm{~nm}$ was excited. Part of the laser energy was coupled out and passed into a Bunsen burner flame doped with NO. The LIF signals from the burner and from the engine were monitored simultaneously. In this way, one could tune the laser onto resonance with hot NO absorption lines and also discriminate against $\mathrm{O}_{2}$ bands. Rayleigh/Mie scattering was suppressed about a factor of $10^{6}$ using several filters. Similarly, the KrFexcimer laser was tuned on to the $(3,0)$ band of the $\mathrm{OH}\left(A^{2} \Sigma-X^{2} I\right)$ transition at $248 \mathrm{~nm}$; the $\mathrm{P}_{2}(8)$ rotational line was excited because it is nearly insensitive to temperature over a wide range (1300$3000 \mathrm{~K}$ ). Fluorescence was detected using a Schott filter WG280.

\section{Results and Discussion}

Figure 5 shows the in-cylinder pressure as a function of crank angle for a typical cycle with Diesel fuel, for an engine speed of $2000 \mathrm{rpm}$ and a fuel mass of $8 \mathrm{mg}$ injected per cycle. At this speed, $12^{\circ}$ crank angle correspond to $1 \mathrm{~ms}$. In the first phase, air flows through the swirl port and the inlet valve into the cylinder and acquires a rotational moment. After intake, the piston rises and the air is compressed; the fuel is then injected under high pressure into the swirl flow, beginning approximately $2^{\circ}$ 


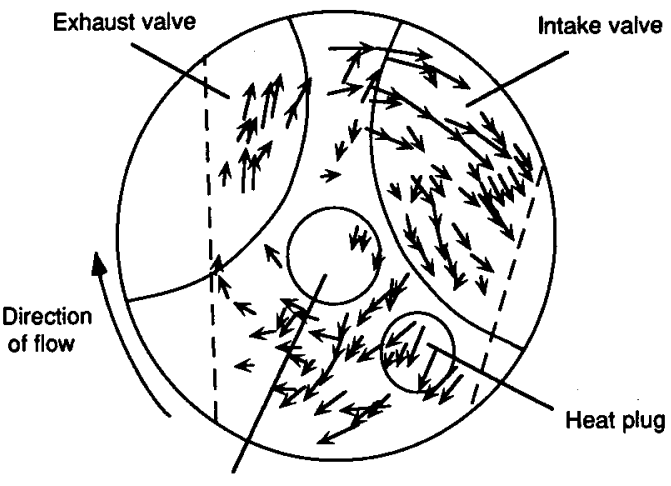

Injection nozzle

FIG. 6. Cycle-averaged flow field at the time of injection (engine speed $2000 \mathrm{rpm}$, motored), plane $5 \mathrm{~mm}$ below the cylinder head.

before top dead center (BTDC). The onset of combustion causes a pressure increase above the compression curve that is converted into mechanical work. It should be noted that the transparent version of the DI diesel engine has a slightly lower maximum compression pressure than the standard engine; this leads to an increased ignition delay.

\section{Visualization of the Flow Field:}

A frame-by-frame analysis of a large number of cycles of the flow field in the piston bowl was made to obtain the cycle-averaged flow field by particle tracking. Only the mean velocity field can be presented because of the small number of useful path lines extractable from each picture. Results for the plane $5 \mathrm{~mm}$ below the cylinder head at the time of injection (Fig. 6) show a well-defined swirl flow. In the middle and outer regions of the piston bowl the velocities are in the range $9-14 \mathrm{~m} / \mathrm{s}$. At the end of the compression phase, the swirl is influenced by squish.

\section{Visualization of Fuel Injection, Autoignition and Combustion in Diesel Combustion:}

The field of view in the piston bowl, shown in Fig. 6, gives the orientation standard for all experiments described in this work. The strength of the interaction between the swirl flow in the combustion chamber and the fuel during injection depends on the engine speed and the injected fuel mass. The fuel vapor is carried along by the transverse flow, whereas the droplets at the point of measurement, because of their inertia, fly nearly unaffected to the walls. The shadowgraphy results visualize the liquid and dense vapor, integrated over the bowl depth. Figs. 7a, b show the propagation a) $0.2^{\circ}$ ATDC

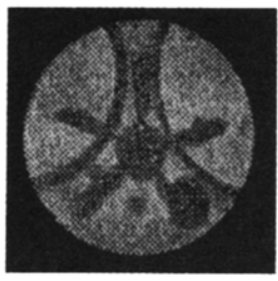

c) $7.8^{\circ}$ ATDC

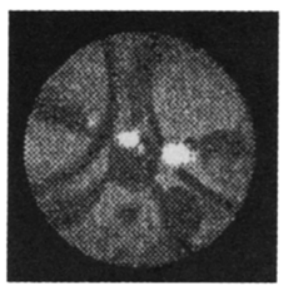

d) $18.6^{\circ}$ ATDC

FIC. 7. Laser shadowgraphy results, Diesel cycle (2000 rpm).

of the fuel sprays from the five-hole nozzle (centered in the bowl). It is seen that the single sprays differ considerably in shape and propagate at various speeds. The wall of the combustion chamber is reached by all sprays, though at slightly differing times.

Autoignition and combustion were observed during the same cycle (Figs. 7c, d), as manifested by the bright emission of soot particles. Autoignition occurs close to the nozzle at several positions and at times differing by up to $0.5 \mathrm{~ms}$ within one cycle. Later, as well as propagation and growing together of the various flame areas, non-combusting regions can be discerned. In the late combustion phase, the compact flame areas fall into several small hot regions. The last emission was observed at about $40^{\circ}$ ATDC.

The fuel distribution was also followed by Mie scattering and LIF. For the images, a scheme of grey shades, corresponding to eight intensity regions was assigned. Mie scattering images taken at crank angles up to $15^{\circ}$ ATDC show progressively weaker signals as the fuel droplets evaporate. At $15^{\circ}$ no Mie scattering was observed, showing that evaporation of the fuel was complete. The LIF and Mie images at $5^{\circ}$ ATDC are compared in Fig. 8. The strong signal in the lower part of the images must be due largely to liquid fuel, since it appears in both fluorescence and Mie images, whereas the signal just to the left must be due to fuel vapor, because it is only present in the fluorescence image. Also, it can be seen that the vapor has been swept around in the direction of the swirl. The reproduc- 

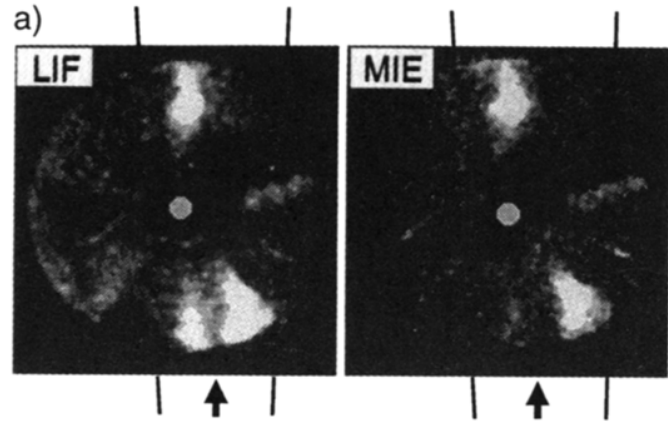

b)
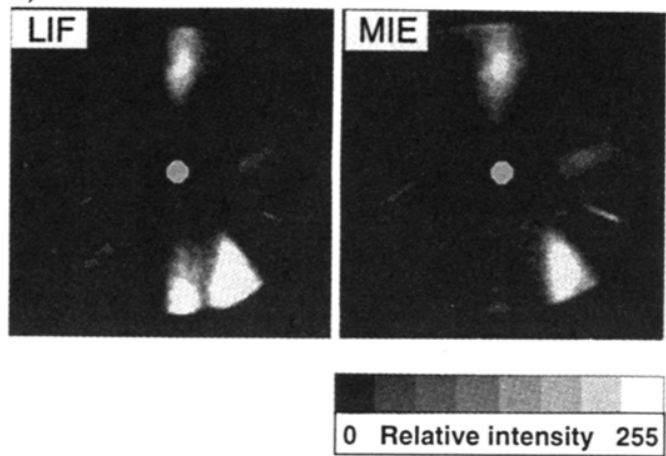

FIG. 8. LIF/Mie scattering images, Diesel cycle $(2000 \mathrm{rpm})$ at $5^{\circ} \mathrm{ATDC}$. The white disc represents the injection nozzle. a) single-shot; b) average of 32 images. The direction and boundaries of the light sheet are marked and are the same for a) and b).

ibility of the images at this stage is evident from the averaged picture. It will be noticed that some signal is obtained beyond the width of the light sheet that enters the chamber; this is due to a) divergence of the light sheet (caused by the sandwich window) and b) multiple scattering resulting from the relatively strong illumination of the piston bowl.

\section{Visualization of n-Heptane Combustion:}

Reasons for using $n$-heptane as fuel were mentioned at the beginning of the paper. However, it has to be pointed out that combustion of $n$-heptane differs from that of Diesel fuel in a number of ways which were discussed in detail elsewhere. ${ }^{4}$ The ignition delay can be about twice as long, allowing time for better fuel/air mixing. As a result, flame emission is much weaker and far less soot is formed. At the engine speed of $1000 \mathrm{rpm}$ and injected fuel mass of $5 \mathrm{mg}$, the maximum pressure was $50 \mathrm{bar}$ and injection began at $7^{\circ}$ BTDC.

The $\mathbf{O H}$ radical was detected previously in Otto engine combustion ${ }^{9,10,12,14}$ and is a key indicator for the detailed chemical kinetics of combustion. Fluorescence of $\mathrm{OH}$ was first detected at $0.2^{\circ}$ ATDC at pressures close to 50 bar with remarkably low off-resonance (background) signals; good fluorescence intensities were obtained up to $23^{\circ}$ ATDC. Fig. 9 shows typical single-shot images (for two different cycles) at $2^{\circ}$ ATDC, which were nearly free of background. Using such information, the time and location of autoignition can be determined more exactly than from flame emission. However, for quantitative analysis of $\mathrm{OH}$ images, information on quenching of the $\mathrm{OH}\left(A^{2} \Sigma, v^{\prime}=3\right)$ state in the relevant pressure range will be needed. At atmospheric pressure, the signal is reduced by only $10 \%$ by quenching effects, ${ }^{17}$ but at pressures in the engine, much stronger effects are expected.

Nitric oxide is formed in the later stages of the combustion process. ${ }^{18}$ 2D-LIF images of NO were obtained which allowed the spatial and temporal development of the NO distribution to be followed qualitatively as a function of time. Figure 10 shows images averaged over 30 shots, taken at approximately 5 and 10 bar respectively. Background signals were determined by tuning the excimer laser off resonance and were subtracted. In contrast to $\mathrm{OH}$, the NO signals depend strongly on the temperature since high energy levels are excited. Quantitative evaluation of the fluorescence signals will also require consideration of quenching of the $D^{2} \Sigma$ state of NO, on which so far very little data are available.

\section{Conclusions}

In summary, the results presented have demonstrated successfully the application of light sheet techniques in a production-like engine and provide useful insight into the processes occurring during a Diesel cycle. First, the flow field was characterized. Fuel spray propagation was visualized by both shadowgraphy and simultaneous LIF and Mie scattering. From the onset of flame emission in the shadowgraphy films, the ignition delay and location can be established, while vaporization can be observed by comparing LIF/Mie images. However, because Diesel fuel is a very complex mixture of components, some of which fluoresce, the images observed must be considered qualitative. Fluorescence quenching effects cannot be accurately assessed in this situation. A more quantitative measure of the fuel distribution could be obtained using a single-component (non-fluorescing) fuel with a suitable fluorescent dopant. This idea was demonstrated recently in experiments in an engine simulator where acetaldehyde was used to mark the fuel distribution and flame front in propane/air combustion. ${ }^{13}$ In Diesel engine combustion, detection of $\mathrm{OH}$ and NO was possible by 2D-LIF at pressures up to 50 bar, though further information (e.g. on temperature fields and quenching effects) 

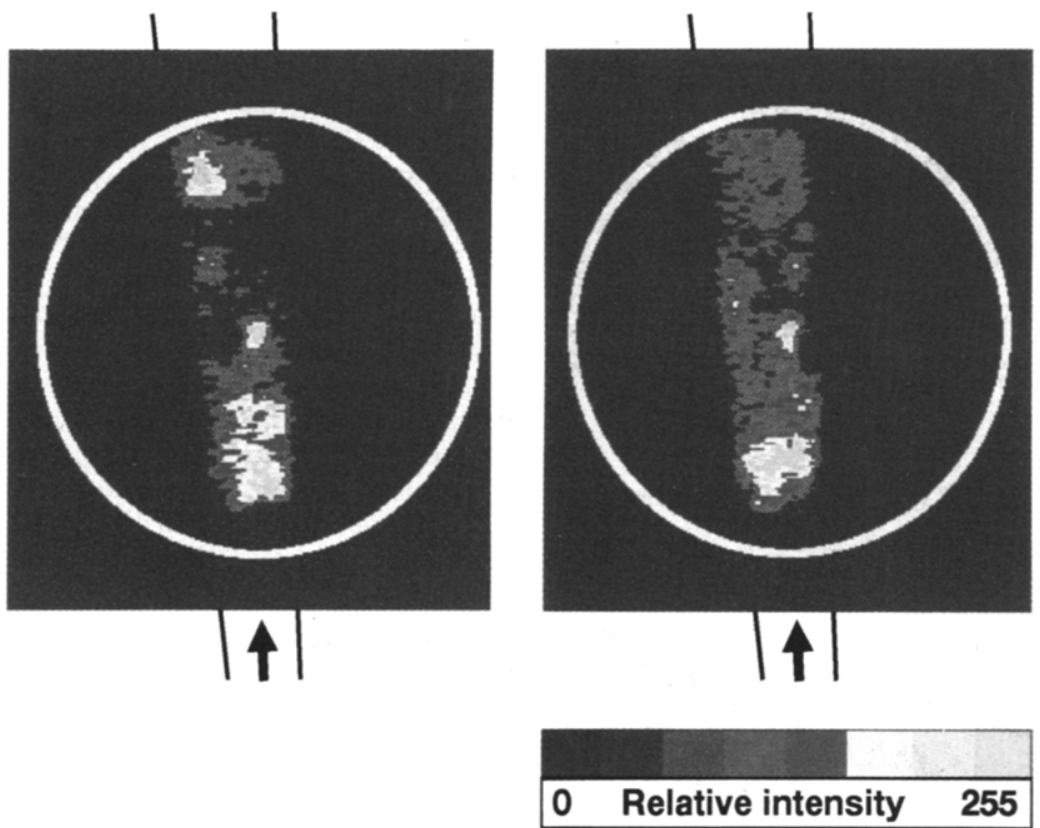

FIG. 9. 2D-LIF of $\mathrm{OH}$ (on the $\mathrm{P}_{2}(8)$ resonance.), (single-shot images, for two different cycles) detected during the $n$-heptane cycle $(1000 \mathrm{rpm})$ at $2^{\circ}$ ATDC.
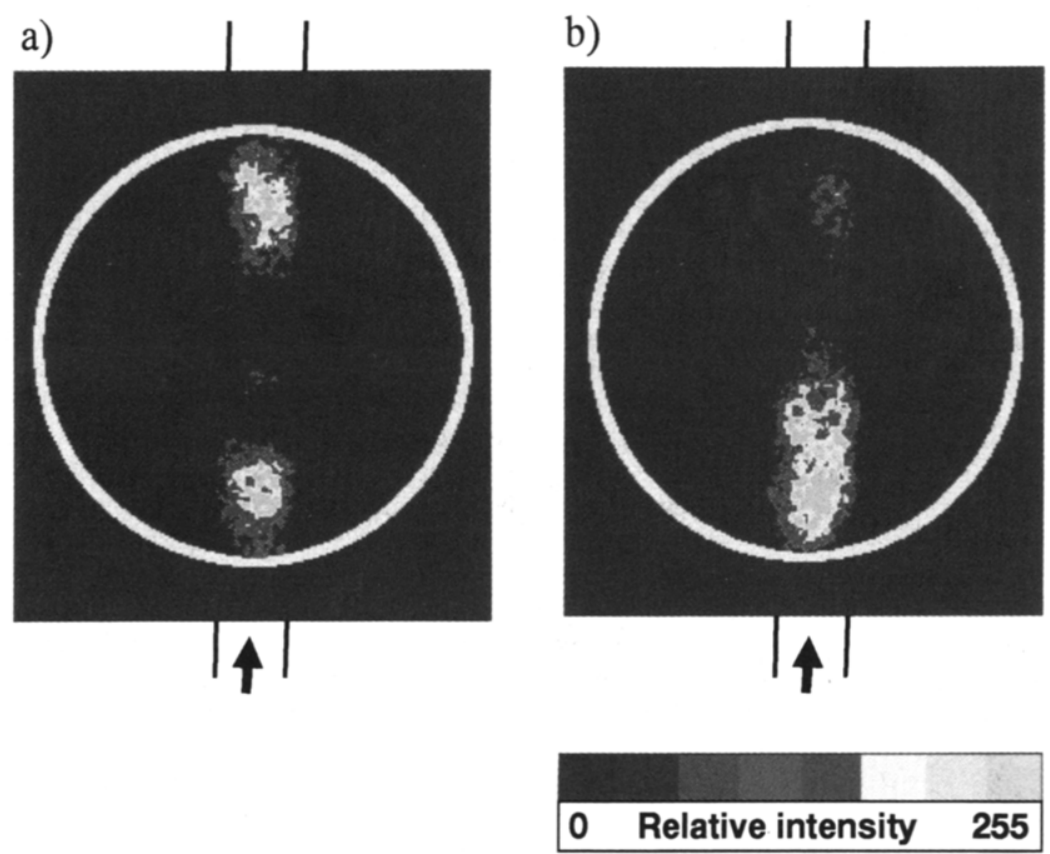

FIG. 10. 2D-LIF of NO, detected during the $n$-heptane cycle $(1000 \mathrm{rpm})$ at a) $47^{\circ}$ ATDC, $10 \mathrm{bar}$ b) $65^{\circ}$ ATDC, 5 bar. 30 images averaged in each case. 
is needed to be able to evaluate the images for model validation. Quenching measurements at high pressures and temperatures are underway in our laboratory using the ultrafast excitation/detection techniques used by us in recent years. ${ }^{19} \mathrm{~A}$ more robust picosecond system is planned to allow in-situ determination, in the engine, of quenching rates along a line.

Having obtained sufficiently quantitative results, the next step would be to compare these data with model calculations, also performed also within the framework of the IDEA project.

\section{Acknowledgement}

Financial support by Volkswagen $A G$ and by the Commission of the European Communities within the framework of the JOULE Programme, by the Swedish National Board for Technical Development and by the Joint Research Committee of European automobile manufacturers (Fiat, Peugeot SA, Renault, Volkswagen, Volvo) within the IDEA Programme is gratefully acknowledged. We also acknowledge the collaboration of W. Ketterle and $\mathbf{H}$. Becker in the early stages of this project.

\section{REFERENCES}

1. Schindler, K.-P. and Hentschel, W.: in Combusting Flow Diagnostics; D. F. G. Durao, M. V. Hetron, J. H. Whitelaw, P. O. Witze (eds.), Kluwer Acad. Publ., 1991, in press.

2. Hentschel, W.: in G. Frankowski, N. Abramson, Z. Füzessy (eds): Application of Metrological Laser Methods in Machines and Systems; Physical Research, Vol. 15, Akademie Verlag, Berlin, 1991.

3. Sмiтн, J. R.: in Flows in Internal Combustion Engines (T. Uzkan, ed.) ASME, New York. p. 67 (1983).

4. Schindler, K.-P., Hentschel, W., Hötger, H., LEIPERTZ, A., MÜNCH, K.-U. AND Voges, H.: VDI-Berichte 922, 435 (1991).
5. Schindler, K.-P., Hesse, A. AND Hentschel, W.: Auto-Tech, C399/19 (IMechE), 1989.

6. Shundoh, S., Kakegawa, T., Tsujimura, K. and KoBayashi, S.: International Symposium COMODIA p. 607 (1990).

7. Khalighi, B.: Exp. Fluids 10, 230 (1991).

8. Reuss, D. L., Adrian, R. J., Landreth, C. C., French, D. T. and Fansler, T. D.: SAE Techn. Paper: Ser. (1990) No. 900053.

9. Felton, P. G., Matzaras, J., Bomse, D. S. And Woodin, R. L.: SAE Techn. Paper Ser. (1988) No. 881633.

10. Schipperijn, F. W., Nagasaka, R., Sawyer, R. F. and Green, R. M.: SAE Techn. Paper Ser. (1988) No. 881631 .

11. Bardsley, M. E. A., Felton, P. G. and Bracco, F. V.: SAE Techn. Paper (1989) No. 890315.

12. Beckek, H., ARNold, A., SUntz, R., Monkhouse, P., Wolfrum, J., Maly, R. AND PfisTER, W.: Appl. Phys. B50 (1990) 473; BECKER, H., Monkhouse, P., Wolfrum, J, Cant, R. S., Bray, K. N. C., Maly, R. and Pfister, W.: Twenty-Third Symposium (International) on Combustion (1990) p. 817.

13. Arnold, A., Becker, H., Stntz, R., Monkhouse, P., Wolfrum, J., Maly, R. and PfisTER, W.: Opt. Lett. 15, 831 (1990).

14. Andresen, P., Meijer, G., Schlëter, H., Voces, H., Koch, A., Hentschel, W., Oppermann, W. AND Rothe, E.: Appl. Opt. 29, 2392 (1990).

15. Hodges, J. T., Baritaud, T. A. and Heinze, T. A.: SAE Techn. Paper 910726 (1990).

16. Felton, P. G., Mantzaras, J., Bardsley, M. E. A. and Bracco, F. V.: SAE Techn. Paper Ser. (1987) No. 87074

17. Gray, J. A. and Farrow, R. L.: J. Chem. Phys. 95, 7054 (1991).

18. Pischinger, F., Schulte, H. and Jansen, J.: VDI-Berichte, Nr. 714, 61 (1988).

19. SChwarzwald, R., Monkhouse, P. AND WOL FRUM, J.: Twenty-Second Symposium (International) on Combustion, The Combustion Institute 1988, p. 1413 and Chem. Phys. Lett. 158, 60 (1989); Köllner, M., Monkholse, P. AND Wolfrum, J.: Chem. Phys. Lett. 168, 355 (1990).

\section{COMMENTS}

Dr. E. Hassel, Technische Hochschule Darmstadt, Germany. (Similar comment submitted by William McLean, Sandia National Laboratories, USA.) 1. Flow field visualization. Is it correct that the determined $2 \mathrm{D}$ velocity field is conditioned at each location on the velocity component perpendicular to the $2 \mathrm{D}$ plane?

2. Quantitative data from $2 \mathrm{D}$ LIF images require to take into account attenuation and scattering of the laser plane by droplets and soot and inhomogeneous illumination by the laser and dirty window. How do you propose that these problems can be eliminated?

Author's Reply. 1. The determined 2D flow field 
is a cycle averaged analysis of the $2 \mathrm{D}$ projection of the 3D velocity vectors onto the light sheet plane.

2. The attenuation of the laser light sheet can be taken into account by measuring the spatially resolved intensity distribution of the light sheet before entering and after exiting the engine. Furthermore it is possible to decrease spoiling of the windows by lubrificants significantly by using e.g. graphite rings and therefore avoid the lubrificants at all. The intensity distribution in the light sheet has been measured in the engine by recording LIF images of a suitable gaseous dopant, added to the air intake. This showed of course a significant broadening by light scattering at the fuel droplet, therefore there are principal limitations to extract quantitative data. However, the qualitative data (see Fig. 8) give useful insights in details of the combustion process. Using $n$-heptane as fuel, the ig- nition delay is longer, thus allowing more time for measurements. And also the formation of soot is decreased drastically.

Derek Dunn-Rankin, University of California, Irvine; USA. You showed a figure comparing LIF from the liquid fuel and fuel vapor that showed fuel vapor swept clockwise from the liquid fuel by swirl. Why is the same feature not visible in all fingers of fuel spray?

Author's Reply. The injection nozzle is tilted; thus not all the fuel sprays reach the light sheet plane at the same time. This can also be seen in the shadowgraphy images of Fig. 7. Also by comparing single shot and averaged images, this effect of the swirl flow is shown to be systematic. 